\title{
Relationship between Third Molar Agenesis and Other Dental Anomalies
}

\author{
Stuti Gulati ${ }^{1}$ Divya Singla ${ }^{1} \quad$ Sanjay Mittal ${ }^{1} \quad$ Mandeep Bhullar ${ }^{1} \quad$ Isha Aggarwal ${ }^{1} \quad$ Abhishek Sharma ${ }^{1}$ \\ ${ }^{1}$ Department of Orthodontics and Dentofacial Orthopedics, Bhojia \\ Dental College and Hospital, Baddi, Himachal Pradesh, India

\begin{abstract}
Address for correspondence Stuti Gulati, Department of College and Hospital, Baddi 173205, Himachal Pradesh, India (e-mail: Stuti.gudu9@gmail.com).
\end{abstract} \\ Orthodontics and Dentofacial Orthopedics, Bhojia Dental
}

\begin{abstract}
Keywords

- agenesis

- dental anomalies

- third molars

Objective The purpose of this study was to find the prevalence of dental abnormalities in patients with third molar agenesis, and a comparison was made for the prevalence of those anomalies within the north Indian natives.

Materials and Methods Pretreatment records of 518 patients were collected. Out of 518 patients whose records were analyzed, 472 patient records were selected on the basis of inclusion and exclusion standards. Panoramic radiographs and dental casts were analyzed in patients who had an absence of at least one third molar in which absence of any other tooth, presence of supernumerary teeth, presence of impacted canines, and peg-shaped lateral incisors were further assessed. The prevalence of these anomalies was compared with a randomly selected group of patients with presence of third molars that served as controls. Statistical analysis was done using the chi-square test $(p<0.05)$ and odds ratio.

Results The incidence of third molar nondevelopment was found to be $19.2 \%$. The presence of other anomalies was $39.5 \%$ in patients with third molar nondevelopment, and difference was statistically significant. The occurrence of impacted canines in patients with absence of third molars was $22 \%$, and presence of third molars was $6.6 \%$. The presence of other dental anomalies, that is, supernumerary teeth and tooth agenesis, was $7.7 \%$ in the agenesis group, which was also higher than that in the control group (3.3\%) but was not statistically significant. The incidence of peg-shaped lateral incisors was similar in both the groups.

Conclusion Impacted canines and total dental anomalies are more often related with absence of third molars than with the presence of third molars.
\end{abstract}

\section{Introduction}

Dental agenesis can be outlined as any situation in which one or additional tooth is missing due to lack of its formation. The third molar is a tooth that is most variable with the time of its formation and has wide variation in its crown and root morphology and presence or absence within the oral cavity. ${ }^{1}$ Third molar development was classified using the system tailored by Bjork et al from the method devised by Gleiser and Hunt ${ }^{2,3}$ for the first molars: stage 1 -crypt formation with no calcification; stage 2-calcification of cusps; stage 3-calcification of half crown; stage 4-calcification of whole crown; and stage 5-root formation. ${ }^{2}$ The teeth were classified developmentally absent when no proof was found within the records that they had been extracted and when lack of mineralization of the tooth crown was seen on the panoramic radiographs. The failure of third molar to develop a condition is named as "congenitally absent."

There is extensive proof suggesting that genes play an elementary role in the etiology of absence of tooth. Vastardis analyzed an outsized family with absence of all second premolars and third molars and recognized a mutation in gene MSX1 on chromosome $4 \mathrm{p}^{4-6}$ Moreover, there seems to be a 
genetic association within the establishment of various dental anomalies. One hereditary condition could lead to totally different phenotypical expressions along with such varied traits.

Frequency of missing third molar has been evaluated in the literature and influenced by the population studied. Levesque et $\mathrm{al}^{7}$ suggested the prevalence to be $9 \%$ for a French-Canadian population; Kruger et $\mathrm{al}^{8}$ established a prevalence of $15.2 \%$ in a New Zealand population; and Lavelle et $\mathrm{al}^{9}$ demonstrated $20 \%$ for a British population. Also, the prevalence in Turkey was $17.3 \%$ in an orthodontic population. ${ }^{5}$ It ranges widely from $0 \%$ among an unspecified sample of cranium Tasmania to $49 \%$ in an unspecified sample of Hungarian craniums. Alternative radiographic studies of white populations found prevalence of 7 to $26 \%$. The prevalence obtained from a sample in Valencia, Spain, was $17.5 \%$.

According to Richardson, third molars are the more usually missing teeth with the range from 9 to $20 \%$ population with one or third molars missing and male-to-female ratio of $3: 2{ }^{3}$ Absence of third molar has been related with agenesis and structure variation of different teeth as well. Garn et al recommended that in the presence of third molar agenesis, there is $13 \%$ times more possibility of absence of another tooth. Some authors have also shown that third molar agenesis appears to be a predisposing factor for reduced size and development of certain teeth. ${ }^{10,11}$

Till now, no information regarding the prevalence of absence of third molar and its association with related dental anomalies has been reported from the north Indian orthodontic population. Therefore, the aims of the study were to research the prevalence of absence of third molars and to find whether there is any relation between nondevelopment of third molars and other dental anomalies and to relate them to a sample of orthodontic patients with third molar present.

\section{Sample}

Panoramic radiographs and study casts of 518 patients were obtained randomly from the orthodontic patient files of Bhojia Dental College and Hospital Baddi, Budh.

\section{Inclusion Criteria}

1. Patients aged between 13 and 28 years

2. Patients without surgical removal or extraction of any tooth

3. Clear radiographs

\section{Exclusion Criteria}

1. Patients with developmental abnormalities

2. Patients with facial clefts or other craniofacial deformity

3. Radiograph with pathologies such as tumor, cysts, etc.

4. Poor-quality radiographs

Third molars were differentiated as congenitally absent when there were no records that they had been extracted, or lack of signs of mineralization of its crown or formation of crypt (seen as a radiolucency) on panoramic radiographs.

Based on inclusion and exclusion standards, 472 patient records were selected for this study.
Dental anomalies checked in patients with missing third molars are described in the following text.

\section{Tooth Agenesis}

Tooth agenesis is the congenital lack of one or more deciduous or permanent teeth. It additionally suggested that the tooth that has not erupted in the oral cavity and is not visible in a radiograph (-Fig. 1).

\section{Hyperdontia/Supernumerary Teeth}

Condition of hyperdontia/supernumerary teeth is defined as an increase in number of teeth in relation to the normal dental formula.

\section{Impacted Canines/Palatally Displaced Canines}

Tooth impaction is a pathologic condition during which a tooth cannot or will not erupt into its normal functioning position, unless facilitated by treatment.

Palatally displaced canine (PDC) is defined as the "developmental dislocation to a palatal site which results in tooth impaction" (-Fig. 2).

\section{Peg-Shaped Maxillary Lateral Incisors}

Peg-shaped maxillary lateral incisor is a condition in which mesiodistal crown width of a lateral incisor is smaller compared with the same dimension of the alternative lateral incisor of the same patient ( - Fig. 3 ).

\section{Statistical Analysis}

The chi-square test results were analyzed to match the presence of dental anomalies in our sample of 472 patients. The prevalence rate of third molar agenesis and other anomalies in the respective samples was calculated by the following formula:

$$
\text { Prevalence rate }=\frac{\text { No of patient with anomalies } \times 100}{\text { No of the total patient }}
$$

The number of the total patient chi-square was used to analyze the results for goodness of fit to compare frequency of dental anomalies in the sample of patients with third molar agenesis with control group.

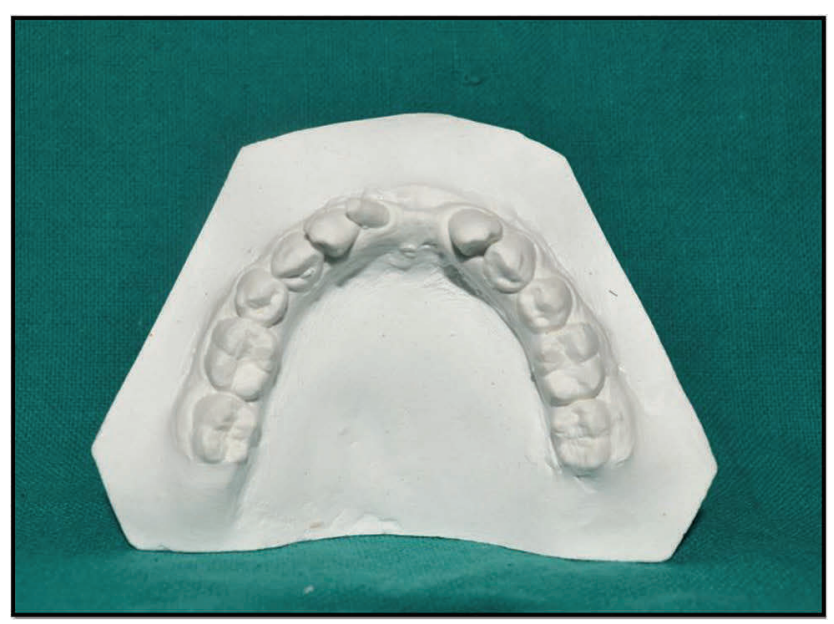

Fig. 1 Absence of other tooth except third molar. 


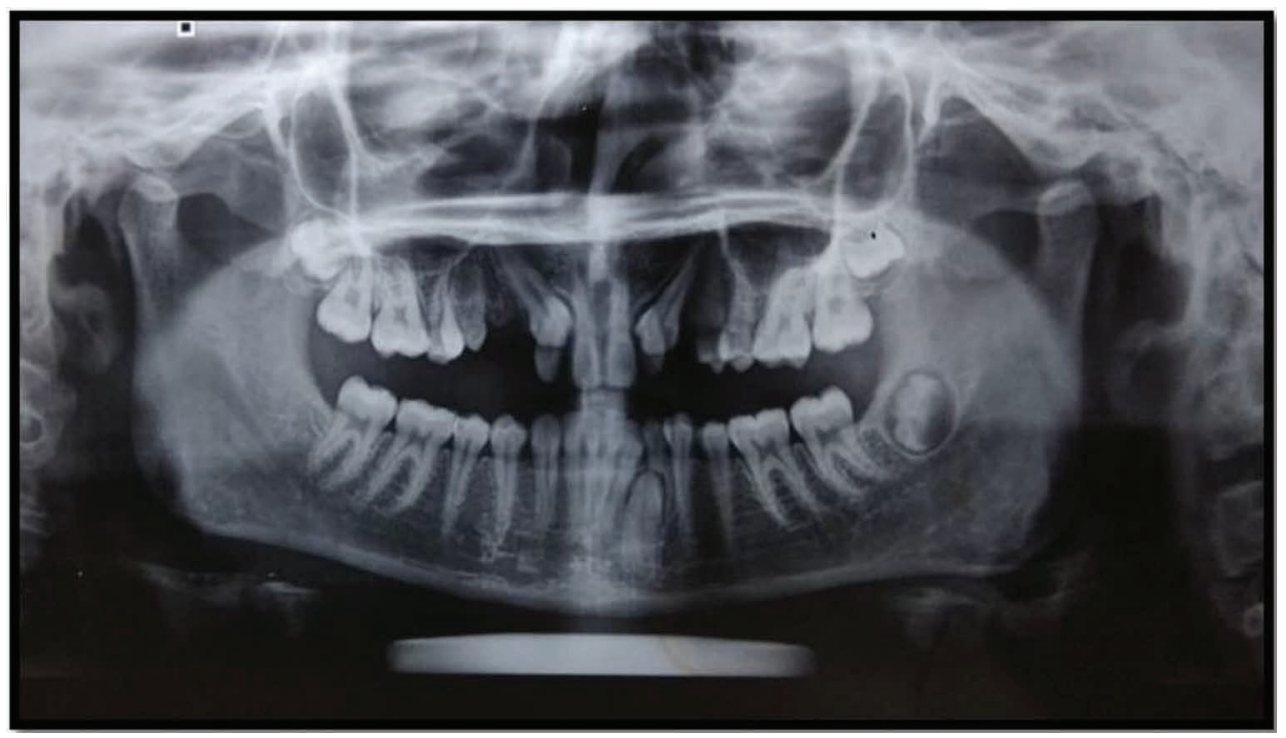

Fig. 2 Impacted canine.

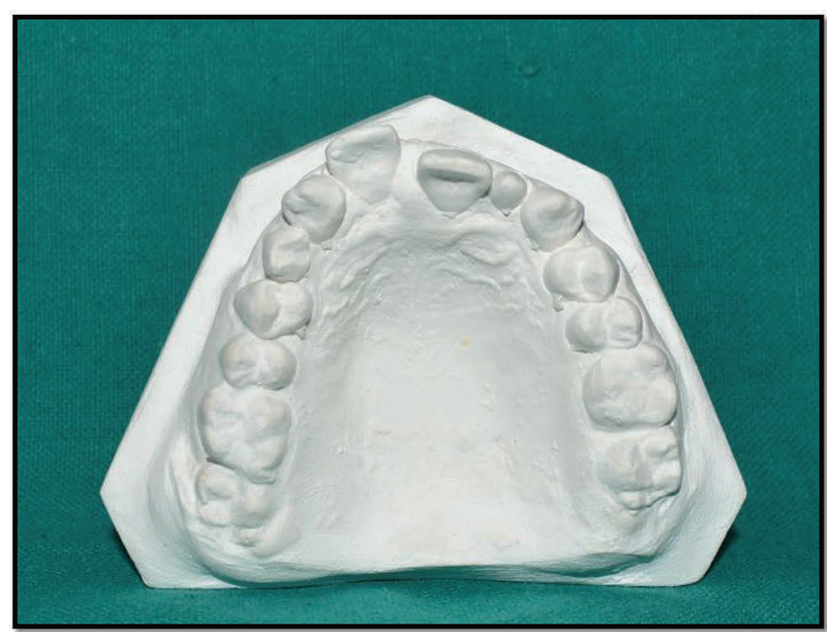

Fig. 3 Peg-shaped lateral incisors.

The odds ratio (OR) was calculated at the $95 \%$ confidence interval to determine the strength of associations between absence of third molars and the presence of dental anomalies investigated.

\section{Results}

Out of the 518 patients whose records were analyzed, 472 met the inclusion and exclusion criteria. Out of the sample of 472 patients, 91 were found to have absence of at least one third molar. This suggested a prevalence of third molar agenesis to be $19.2 \%$ in our sample. Ninety-one patients without third molars agenesis were taken as control group.

The prevalence of other dental anomalies was found to be $39.5 \%$ in the third molar agenesis sample whereas it was $14 \%$ for the control sample. The difference between the two groups was statistically significant. Impacted canines were found to have a higher prevalence rate (22\%) in the third molar agenesis group than the control group (6.6\%). The difference was found to be statistically significant. Presence of supernumerary teeth and absence of other teeth also had a higher prevalence rate in the third molar agenesis group than the control, but the difference was not statistically significant. No difference was found in the prevalence rate of peg-shaped lateral incisors between the two groups (-Fig. 4).

\section{Discussion}

Masseler et al reported various ages of development of third molars. According to them, third molar crypt formation starts at the age of 3 to 4 years, calcification starts at 7 to 10 years, and calcification of crown is completed at the age of 12 to 16 years. According to Garn et al and Gravely, the upper age limits for development of third molars is 13 years. Thus, patients older than 13 years were incorporated in our study to check out any false-negative errors. Subsequent panoramic radiographs were evaluated in cases within which it was absolutely difficult to judge the nondevelopment of third molars within the initial radiographs. ${ }^{13}$

The frequency of third nondevelopment in this study was $19.2 \%$. As per Levesque et al, the frequency of third molar nondevelopment for the French-Canadians was 9\%, as per Kruger et al, it was $15.2 \%$ for the New Zealand population, and as per Sisman et al, ${ }^{14}$ it was $16.8 \%$ for the Turkish population. ${ }^{5}$ As racial variation, nature of one's diet, degree of use of masticatory apparatus, and genetic inheritance can affect the jaw size, tooth size, and facial growth. Differences can be seen among studies of the prevalence of third molar teeth performed in numerous populations. Moreover, variation in sample sizes, statistical methods, and diagnostic standards may also justify these variations. Patients in our study were from a study sample representing patients of various dietary habits and a mean middle socioeconomic level from rural and concrete backgrounds. This ensured that the study sample was representative of the north Indian orthodontic population as an entirety.

The presence or absence of third molars from oral cavity has been related to genetically predetermined skeletal and dental factors. Ohio et al (1961) examined 172 white 


\section{Patients}

91 Patients with third molar agenesis
91 patients with

third molar present

(control group)

\begin{tabular}{|c|c|c|c|c|c|}
\hline \multirow[t]{2}{*}{ Dental Anomaly } & \multicolumn{2}{|c|}{ Prevalence rate } & \multirow{2}{*}{$\begin{array}{l}\text { Chi-sq } \\
\text { value } \\
\text { (P-value) }\end{array}$} & \multirow{2}{*}{$\begin{array}{l}\text { Odds } \\
\text { ratio }\end{array}$} & \multirow[t]{2}{*}{ C.I. } \\
\hline & $\begin{array}{l}\text { Third molar } \\
\text { agenesis }\end{array}$ & $\begin{array}{l}\text { Third molar } \\
\text { presence }\end{array}$ & & & \\
\hline Impacted teeth & $22 \%(20 / 91)$ & $6.6 \%(6 / 91)$ & $\begin{array}{l}8.79 \\
(0.003)\end{array}$ & 3.99 & $\begin{array}{l}1.52- \\
10.47\end{array}$ \\
\hline Missing teeth & $7.7 \%(7 / 91)$ & $3.3 \%(3 / 91)$ & $\begin{array}{l}1.69 \\
(0.193)\end{array}$ & 2.44 & $0.61-9.77$ \\
\hline $\begin{array}{l}\text { Supernumerary } \\
\text { teeth }\end{array}$ & $7.7 \%(7 / 91)$ & $3.3 \%(3 / 91)$ & $\begin{array}{l}1.69 \\
(0.193)\end{array}$ & 2.44 & $0.61-9.77$ \\
\hline Peg lateral & $2.2 \%(2 / 91)$ & $2.2 \%(2 / 91)$ & - & - & - \\
\hline Overall & $39.5 \%(36 / 91)$ & $14 \%(14 / 91)$ & $\begin{array}{l}13.35 \\
(0.002)\end{array}$ & 3.60 & $\begin{array}{l}1.77- \\
7.30\end{array}$ \\
\hline
\end{tabular}

Fig. 4 Prevalence rate of third molar agenesis with dental anomalies compared with reference value.

children with delayed formation of different teeth and disturbances in the tooth eruption sequence. They concluded that third molar nondevelopment was an extreme expression of the factors delaying tooth formation over a developmental period ranging from the first month of life (first molar) to at least the eighth year (third molar).

Garn and Lewis (1960) ascertained that patients with nondevelopment of third molars had increased prevalence of missing other teeth. The prevalence of nondevelopment of permanent teeth in the group with third molar nondevelopment was 13 times higher than missing teeth in the control group..$^{10}$

In our study, the incidence of absence of alternative teeth was higher as compared with control group but was not statistically significant. Our study, therefore, confirmed the results of Garn and Lewis, which show alternative physical dental traits related to the occurrence of nondevelopment of the tooth. It contributes to mounting proof that agenesis and its associated abnormalities are influenced by genetics. As one genetic defect might create various anomalies, indicating two or more dental anomalies in the same patient may be due to common genetic origin. Studies of families as well as investigations of the association of agenesis and other types of dental anomalies previously highlighted the role compete by genetic mechanisms in the etiology of various dental anomalies. However, Shah and Boyd concluded that third molar nondevelopment was not related to higher prevalence of hypodontia in alternative teeth. This discrepancy might be due to variation in sampling ways and the patients' age distribution. ${ }^{15}$

This study also evaluated the presence of impacted or palatally displaced canine in relation to missing third molars. The prevalence rate of PDC or impacted canines was significantly higher in patients with missing third molars as compared with control group.

These pieces of information confirm earlier results that the PDC presents an incident pattern that implies genetic origin. Peck et al determined that PDC patients presented a considerably increased prevalence of nondevelopment of second premolars and third molars. ${ }^{16}$

A study conducted by Bacetti investigated the relation between absence of second premolar and presence of supernumerary teeth and found no correlation between them. ${ }^{17}$ In 
this study, the prevalence of supernumerary teeth was more in the group having absence of third molar as compared to the control group, but the difference was not statistically significant. The incidence of peg-shaped lateral incisors was also not affected by the presence or absence of third molars in our study. Their incidence was found to be the same in both the groups. In 1997, Proffit mentioned that the foremost common abnormality is size variation, notably of the upper lateral incisors. Altug-Atac and Erdem showed the prevalence of peg-shaped maxillary lateral incisors was $1.51 \%$ leading to the second most frequent dental anomaly. Surprisingly, in the study published 50 years ago, peg lateral teeth were a small minority of dental anomalies (0.33\%); however, in our study peg lateral is the least present anomaly due to distinction in population cluster and native environmental factors. ${ }^{18}$

\section{Conclusions}

- The prevalence rate of nondevelopment of third molar was found to be $19.2 \%$ in our sample.

- Impacted canines and PDCs are more commonly associated with the nondevelopment of third molars.

- Patients with absence of third molars have more prevalence rate of associated dental anomalies.

\section{Conflict of Interest}

None declared.

\section{References}

1. Almpani K, Kolokitha OE. Role of third molars in orthodontics. World J Clin Cases 2015;3(2):132-140

2. Glesier J, Hunt EE. The permanent mandibular first molar: its calcification eruption and decay. Am J Phys Anthrop. 1955;253-283

3. Richardson M. Late third molar genesis: its significance in orthodontic treatment. Angle Orthod 1980;50(2):121-128

4. Vastardis H. The genetics of human tooth agenesis: new discoveries for understanding dental anomalies. Am J Orthod Dentofacial Orthop 2000;117(6):650-656
5. Garib DG, Peck S, Gomes SC. Increased occurrence of dental anomalies associated with second-premolar agenesis. Angle Orthod 2009;79(3):436-441

6. Nuvvula S, Kiranmayi M, Shilpa G, Nirmala SV. Hypohyperdontia: Agenesis of three third molars and mandibular centrals associated with midline supernumerary tooth in mandible. Contemp Clin Dent 2010;1(3):136-141

7. Levesque GY, Demirijian A, Tanguay R. Sexual dimorphism in the development, emergence, and agenesis of the mandibular third molar. J Dent Res 1981;60(10):1735-1741

8. Kruger E, Thomson WM, Konthasinghe P. Third molar outcomes from age 18 to 26 : findings from a population-based New Zealand longitudinal study. Oral Surg Oral Med Oral Pathol Oral Radiol Endod 2001;92(2):150-155

9. Lavelle BLC, Ashton EH Flinn MR. Cusp Pattern, Tooth size and third molar agenesis in the human mandibular dentition. Archs Oral Biol.1970;(15):227-237

10. Garn SM, Lewis AB. The relationship between third molar agenesis and reduction in tooth number. Angle Orthod 1960;32:14-18

11. Celikoglu M, Bayram M, Nur M. Patterns of third-molar agenesis and associated dental anomalies in an orthodontic population. Am J Orthod Dentofacial Orthop 2011;140(6):856-860

12. Massler M, Schour I, Poncher HG. Developmental pattern of the child as reflected in the calcification pattern of the teeth. Am J Orthod Dentofacial Orthop 1941;62:33-67

13. Kajii T, Imai T, Kajii S, Iida J. Presence of third molar germs in orthodontic patients in Japan. Am J Orthod Dentofacial Orthop 2001;119(3):245-250

14. Sisman Y, Uysal T, Gelgor IE. Hypodontia. Does the prevalence and distribution pattern differ in orthodontic patients? Eur J Dent 2007;1(3):167-173

15. Shah RM, Boyd MA. The relationship between presence and absence of third molars hypodontia of other teeth. J Dent Res 1979;58(1):544

16. Peck S, Peck L, Kataja M. Prevalence of tooth agenesis and peg-shaped maxillary lateral incisor associated with palatally displaced canine (PDC) anomaly. Am J Orthod Dentofacial Orthop 1996;110(4):441-443

17. Baccetti T. A controlled study of associated dental anomalies. Angle Orthod 1998;68(3):267-274

18. Altug-Atac AT, Erdem D. Prevalence and distribution of dental anomalies in orthodontic patients. Am J Orthod Dentofacial Orthop 2007;131(4):510-514 